\title{
A Critical Review on Innovative Utilization of Bamboo in Rural Road Construction
}

\author{
Dr. Jayeshkumar Pitroda ${ }^{1}$, Hardik Pankhaniya ${ }^{2}$, UrvishPachani $^{3}$, Saurabh $_{\text {Agravat }}{ }^{4}$, \\ Prakash Parmar \\ ${ }^{1}$ Assistant Professor, Civil Engineering Department, B.V.M. Engineering College, Vallabh \\ Vidyanagar-Gujarat-India \\ 2,3,4,5 Student of final year B.E, Civil Engineering Department, B.V.M Engineering College, Vallabh \\ Vidyanagar-Gujarat-India
}

\begin{abstract}
Rural Road connectivity is a key component of rural development, since it promotes access to economic and social services, thereby generating increased agricultural productivity, non-agriculture, employment as well as non-agricultural productivity, which in turn expands rural growth opportunities and real income through which poverty can be reduced. Recently, in the attention in response to global warming issues and sustainable society, the manufacturing using natural materials has become active. Present day construction works use concrete as a basic material. To achieve Tensile strength, Steel is used as reinforcement because concrete is Brittle in tensile strength. Most commonly encountered problems in Steel are corrosive, expensive, etc. Therefore, studies are going on to use Bamboo as reinforcement in concrete and as a structural material because of its beneficial characteristics. Some of the fibers that can use in production of Fiber Reinforced Concrete (FRC) are Aluminum, Coir, Jute, Carbon, Steel, etc. The Bamboo fibers are also used in concrete as a natural fiber to produce Bamboo Fibers Reinforced Concrete (BFRC) to impart some desirable properties to concrete. The mixing of small, closely spaced and evenly distributed fibers to concrete avoids cracking and significantly develop the Cracking arrestors, Impact strength, Tensile strength, Fatigue resistance, and Wear and Tear. This has been proved. The concrete Ductility is augmented by mixing of fibers. Bamboo is a multipurpose reserve categorized by a large ratio of strength to weight and its ease of work with simple tools. So Rural Cement Concrete road can be constructed with the use of the bamboo fiber and according to so many favorable mechanical property of the bamboo fiber, we canuse of bamboo fiber in rural road construction and increase the strength of road and increase the durability.
\end{abstract}

Keywords: Rural Road, Agricultural, Construction, Bamboo, Fibre

\section{INTRODUCTION}

About 600 million people of India live in nearly 6 lakh villages scattered all over the country. Access roads provide the means to bring the rural population on to the main stream.Notwithstanding the efforts made, over the years, at the State and Central level, through different programs, about $40 \%$ of habitations in the country are still not connected by all-weather roads. The rural connectivity is expected to have many positive impacts on economy, agricultural, employment and social services to rural masses.

For the construction of Rural Roads, Indian Roads Congress has brought out Rural Road Manual IRC SP:20-2002 for design and construction. The design is based on the CBRvalue of the soil sub-grade and the 10 years projected cumulative traffic with an assumed 6\%traffic growth per year. Based on this concept, normally two layers of WBM with $75 \mathrm{~mm}$ thickness is laid over the granular sub-base with suitable material having minimum $15 \% \mathrm{CBR}$. And for the Rural Roads Connectivity CC road is widely use in the India. And for the construction of the CC road main ingredient is the aggregate, sand, and water. But for increase the Strength and lifespan we are add some other material. For that we can use the locally available materials, including marginal and industrial waste materials are utilized, it could be possible to reduce the cost of road construction. Several types of new materials are tried to establish the efficacy of new materials in road construction. However, the use of new materials and technologies is not becoming popular owing to certain procedural constraints as well as lack of awareness and therefore appropriate steps may have to be taken for popularizing the new 
technologies for building better rural roads with less cost.Adoption of such technique may also result in the conservation of natural resources, energy environment.

Bamboo is a multipurpose reserve categorized by large ratio of strength to weight and its ease of work with simple tools. It is one of the rapidly growing natural reserves also it is easily and locally available. Bamboo had been using for construction even from early times. It can be used as Technical and Non-Technical ways. For building the houses our forefathers used Bamboo as basic material. Because of its high strength to weight ratio, traditionally it has been used in varied living facility and tools. This property is due to the longitudinal alignment of fibers. Bamboo fibers have better modulus of elasticity than any other natural material. The longer is the fiber the higher it gives the tensile strength.Addition of Bamboo fibers to the concrete elevates the mechanical strength and tensile strength. It has low specific weight too. As the bamboo fibers are susceptible to the biological attacks; that is from fungus, termites etc. It was given treatment of Wood Guard's anti-termite solution. In practice, in addition to the extraction of bamboo fibers in controlled way from bamboo trees it is mandatory to fabricate the bamboo based composites.

\section{LITERATURE REVIEW}

The following are the previous research review based on bamboo in road construction.

Patel Pratima, et al. (2013) studied that Bamboo culms are cylindrical shells and are divided by nodes as solid transversal diaphragms. The strength distribution is more uniform at the bottom of bamboo than at the top or at the middle of it since it is subjected to maximum bending stress due to wind at the top portion of the culms. Applying the load at they had their observations recorded. In the plain slab panel test specimen, the first crack occurred vertically from the point of load application which was flexure crack and the crack was widened. In singly reinforced concrete slab panel the crack was seen to be going in a vertical direction. Then the crack got widened.The crack was rising very smoothly and slowly. From various tests conducted, results of Elasticity of Bamboo strips are evaluated $5098 \mathrm{~N} / \mathrm{mm}^{2}$ which is comparative same as steel. Same as load carrying capacity of bamboo strips with concrete is justifying with steel reinforcement. Replacement of steel reinforced can be possible by using Bamboo as bonding element in concrete. Bamboo is naturally available material as compared to steel but properties as well workability of Bamboo is compatible.(1)

AkashPriyadarshee et al. (2014) trying to use the bamboo in the construction of the Low volume rigid pavement and he said that the bamboo was placed $50 \mathrm{~mm}$ from the top of the pavement such that it would serve to control cracking during initial setting and also assist in the control of cracking that could occur due to temperature variations. The bamboo mesh of $250 \times 250 \mathrm{~mm}$ was placed on $100 \mathrm{~mm}$ wooden spacers, which ensured the desired $50 \mathrm{~mm}$ cover to the reinforcement would be maintained. The wooden blocks were removed as pouring of concrete progressed. And according to the result the ultimate tensile strengths of bamboo splints and mild steel are $133.50 \mathrm{~N} / \mathrm{mm}^{2}$ and $255.00 \mathrm{~N} / \mathrm{mm}^{2}$ respectively with corresponding yield strengths of $68.75 \mathrm{~N} / \mathrm{mm}^{2}$ and $207.50 \mathrm{~N} / \mathrm{mm}^{2}$ which makes bamboo an attractive substitute to steel in tensile loading applications.(2)

KannanRassiah et al. (2015) studied of characterization of bamboo-glass fiber reinforced polymer matrix hybrid composite found that the mechanical properties of the bamboo-glass fiber reinforced polypropylene hybrid systems depend on fiber weight ratios, fiber length, and adhesion characteristics between the fibers and the matrix. The result with different bamboo fibers $3 \mathrm{~mm}$ and $6 \mathrm{~mm}$ were obtained using mold press method and $10 \%$ to $40 \%$ bamboo fiber was loading with and without MAPP. It is seen that the average tensile strength only showed a slight improvement when bamboo fiber content was increased from 10 to $30 \%$, and it was dropped by $16 \%$ at $40 \%$ (by weight) fiber content compared to the case of $10 \%$ (by weight) fiber content.(3)

S.K. Jain et al. (2015) studied that, for $26-35 \mathrm{~mm}$ diameter range, the average shear strength for 30 $\mathrm{mm}$ and $60 \mathrm{~mm}$ length of bamboo sample with node was $19.43 \mathrm{~N} / \mathrm{mm}^{2}$ and $9.78 \mathrm{~N} / \mathrm{mm}^{2}$ and the average shear strength for $30 \mathrm{~mm}$ and $60 \mathrm{~mm}$ length of without node bamboo sample was 14.02 $\mathrm{N} / \mathrm{mm}^{2}$ and $8.78 \mathrm{~N} / \mathrm{mm}^{2}$. In the $36-45 \mathrm{~mm}$ diameter range, the average shear strength for $40 \mathrm{~mm}$ and $80 \mathrm{~mm}$ length of bamboo sample with node was $17.65 \mathrm{~N} / \mathrm{mm}^{2}$ and $8.11 \mathrm{~N} / \mathrm{mm}^{2}$ and the average shear strength for $40 \mathrm{~mm}$ and $80 \mathrm{~mm}$ length of bamboo sample without node was $10.91 \mathrm{~N} / \mathrm{mm}^{2}$ and 7.21 $\mathrm{N} / \mathrm{mm}^{2}$. In the 46- $55 \mathrm{~mm}$ diameter range, the average shear strength for $50 \mathrm{~mm}$ and $100 \mathrm{~mm}$ length of bamboo sample with node was $9.79 \mathrm{~N} / \mathrm{mm}^{2}$ and $8.01 \mathrm{~N} / \mathrm{mm}^{2}$ and the average shear strength for 50 $\mathrm{mm}$ and $100 \mathrm{~mm}$ length of bamboo sample without node was $8.89 \mathrm{~N} / \mathrm{mm}^{2}$ and $6.54 \mathrm{~N} / \mathrm{mm}^{2}$.(4) 
Shakeel Ahmad et al. (2014) observed that the cubes after 28 days of curing is marginally increase in ultimate strength of concrete by reinforcing it with bamboo fibers. The reason for this low strength at early stage may be due to weak bond between bamboo fibers and concrete in early days. The fibers surface friction must be increased to see the effect of the increase the strength of bamboo reinforcement concrete in early stage but due to lack of time, it could not be done. The stress strain curve for bamboo reinforced concrete cube is almost linear showing the elastic behavior. The results show that modulus of elasticity of concrete increases on addition of bamboo fibers. For plain concrete it has been found to be $23.30 \mathrm{kN} / \mathrm{mm}^{2}$ whereas for fibers reinforced concrete it gains as high as $47.62 \mathrm{kN} / \mathrm{mm}^{2} .(5)$

Thingujam Jackson Singhet. al. (2014) have given a critical review of the characterization for natural fiber reinforced composite. The mechanical properties of the natural fiber composites (bamboo, sisal) primarily depend upon the fiber interfacial adhesion. Though the natural fibers are superior in properties, but due to its hydrophilic nature, it possesses poor bonding nature with the hydrophobic polymer matrix. This has resulted in the degradation of its mechanical properties. The optimum fiber length, loading and low moisture absorption nature of the fibers have improved the mechanical properties of the composite. The addition of flame retardants has resulted in the increase of thermal stability of the composite. The natural fiber reinforced composites got high potential of replacing the conventional material used in the electrical appliances.(6)

S.P. Kurhekar et al. (2015) observed that the tensile strength of bamboo is very high and can reach $370 \mathrm{~N} / \mathrm{mm} 2$. This makes bamboo an alternative to steel in tensile loading applications. This is due to the fact that the ratio of tensile strength to specific weight of bamboo is six times greater than that of steel and flexural strength of bamboo is good and can be used as reinforcement in R.C.C. structure for low cost housing. (7)

Bindu M. et al. (2016) studied that Bamboo is a multipurpose reserve categorized by large ratio of strength to weight and its ease of work with simple tools The Bamboo fibers are used in concrete as a natural fiber top roduce Bamboo Fibers Reinforced Concrete (BFRC) to impart some desirable properties to concrete. Bamboo fibers have better modulus of elasticity than any other natural material. The longer is the fiber the higher it gives the tensile strength. Addition of Bamboo fibers to the concrete elevates the mechanical strength and tensile strength. It has low specific weight too. As the bamboo fibers are susceptible to the biological attacks; that is from fungus, termites etc... It was given treatment of Wood Guard's anti-termite solution. In practice, in addition to the extraction of bamboo fibers in controlled way from bamboo trees it is mandatory to fabricate the bamboo based composites.(8)

Abdul Ahadet al. (2015) have given a critical literature review of the application of Steel fiber in rigid road construction for increasing the strength, life-period and reducing overall cost of road construction.Steel fibers are economical as well as effective in increasing the strength of pavement. It is one of the good alternative solutions to the modern transportation system of developing countries like India. By the use of steel fibers, the thickness of road reduces up to $25 \%$ to $30 \%$ with the increase in the durability of the road pavement, so it can decrease the Overall cost of the road construction. The different type of loads is easily movable without the construction of any special type of pavement. It is totally favorable to the Government of the specific country in the economical investment on the roads. And it is also helpful to reduce the material consumption on the construction of roads. Because of reducing the concrete or material usage, the ill effect of cement usage reduces on the environment. It also possesses high strength, so it has long durability. (9)

AjinkyaKaware et al. (2013) stated that water absorption of bamboo is quite high. To reduce this effect seasoning or other suitable treatment should be given. Tensile strength of bamboo is good and can be used as reinforcement in R.C.C. Construction. As bamboo is weak in shear it cannot be used as shear reinforcement in R.C.C structure. Moisture content of bamboo changes according to topography and climatic condition. Moisture content directly affects the strength of bamboo. According to study by researchers in world, in next 60 years' steel production will be reduce hence a utilization of natural and eco-friendly options like bamboo should be used. Bamboo is deteriorating in open atmosphere hence it should be treated by epoxy coating, tar coating etc. Bamboo shows ductile behavior as in steel. (10)

Following figure 1 shows historical development in the area of Bamboo and Bamboo use in construction industry with respect to time. 


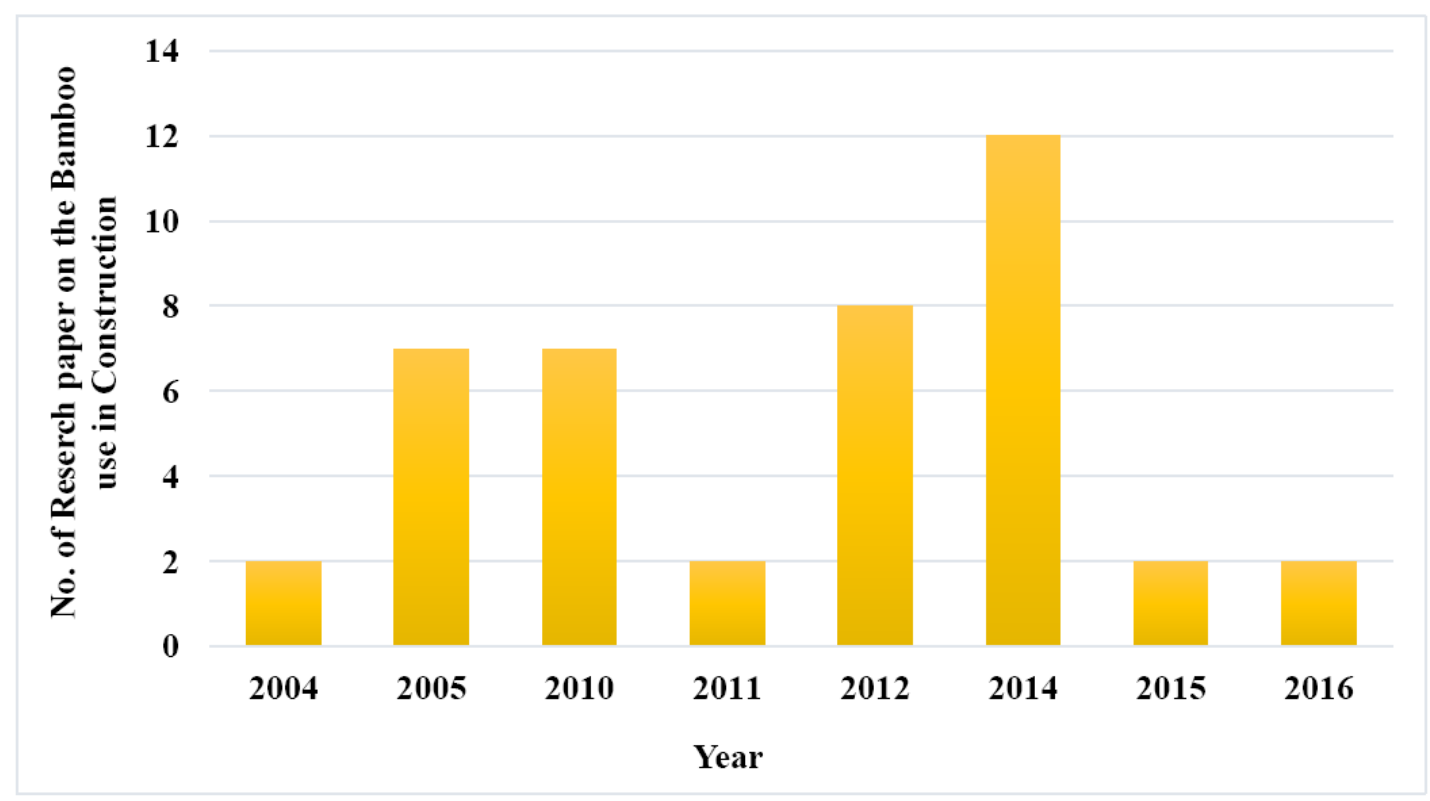

Figure1. Historical Development in the Area of Bamboo use in Construction

\section{Conclusions}

Based on Literature Review the following conclusions are drawn:

1. From the Experiment, the elasticity of Bamboo strips is evaluated $5098 \mathrm{~N} / \mathrm{mm}^{2}$, which is comparative same as steel. And also load carrying capacity of bamboo strips with concrete is similar to the steel reinforcement.

2. He gives the design of the Low volume rigid pavement with the use of bamboo for the rural road. And according to result we can say that the bamboo is an attractive substitute to steel in tensile loading applications and it can be an alternative of the steel in the low volume rigid pavement construction.

3. The tensile strength is also dependent on the weight ration of bamboo and cement used for the making the Bamboo Fiber concrete. So it is seen that when the content of bamboo is an increase in the bamboo fiber concrete, so their strength will be increased up to some limited content of Bamboo fiber.

4. The shear strength is increase with increase in the diameter of bamboo, and decrease with increase in the length. Shear strength is high with the in the with node bamboo, while shear strength is low in the without node bamboo.

5. The stress strain curve of bamboo reinforced concrete cube is almost linear showing the elastic behavior. And Modulus of elasticity of concrete increases on addition of bamboo fibers.

6. The mechanical properties of the natural fiber (bamboo) composites primarily depend upon the fiber interfacial adhesion. Though the natural fibers are superior in properties, but due to its hydrophilic nature, it possesses poor bonding nature with the hydrophobic polymer matrix

7. Bamboo cannot prevent cracking of concrete under ultimate load but from flexural test of bamboo reinforced beam, it has been seen that using bamboo reinforcement in concrete can increase the load carrying capacity of beam having same dimensions.

8. Bamboo Fiber shows good potential and increased strength and acts as a crack resistor. The workability decreases with the increase in the length of the fiber. Inclusion of fibers improves the mechanical properties of the concrete.

9. By the use of the different fiber in the construction of the rigid pavement, it results in the reduction thickness because of the strength of the Concrete is increase but by the use of steel fibers the thickness of rigid pavement reduces up to $25 \%$ to $30 \%$ with the increase in the durability of the road pavement, so it can decrease the Overall cost of the road construction.

10. Water absorption of bamboo is quite high. To reduce this effect seasoning or other suitable treatment should be done on the bamboo surface. And Bamboo is deteriorating in open atmosphere hence it should be treated by epoxy coating, tar coating etc. 


\section{ACKNOWLEDGMENT}

The Authors thankfully acknowledge to Dr. C. L. Patel, Chairman, Charutar Vidya Mandal, Er. V. M. Patel, Hon. Jt. Secretary, Charutar Vidya Mandal, Prof. (Dr.) Indrajit Patel, Principal, B.V.M. Engineering College, Dr. L. B. Zala, Head and Professor, Civil Engineering Department, Prof. J. J. Bhavsar, Associate Professor, Civil Engineering Department, B.V.M. Engineering College, Vallabh Vidyanagar, Gujarat, India for their motivations and infrastructural support to carry out this research.

\section{REFERENCES}

[1] Patel Pratima, "Performance Evaluation of Bamboo as Reinforcement in Design of Construction Element"International Refereed Journal of Engineering and Science (IRJES) ISSN (Online) 2319-183X, 2319-1821 Volume 2, April-2013

[2] AkashPriyadarshee, Anil Kumar Chhotu, VikasKumar, "Use of Bamboo in Low Volume Rigid Pavement as Reinforced Material: A Review" Journal of Civil Engineering and Environmental Technology Print ISSN: 2349-8404; Online ISSN: 2349-879X; Volume 1, Number 3; August2014

[3] KannanRassiah, M.M.H Megat Ahmad, Aidy Ali, HaeryipSihombing, “The Effect of Bamboo Strip on The Impact and Hardness Performances of Unsaturated Polyester Composites"Journal of Applied Science and Agriculture, Pages: 8-12,Special-2015

[4] S.K. Jain, S.P. Kurhekar,S. Kothe, "Effect of dimensions of bamboo on their strength properties" International Journal of Agricultural Engineering, Volume 8, Issue 2, October-2015

[5] Shakeel Ahmad, AltamashRaza, and Hina Gupta, "Mechanical Properties of Bamboo Fiber Reinforced Concrete" 2nd International Conference on Research in Science, Engineering and Technology (ICRSET'2014), March-2014

[6] Thingujam Jackson Singh, SutanuSamanta, "Characterization of Natural Fiber Reinforced Composites-Bamboo and Sisal: A Review" IJRET: International Journal, Volume: 03 Special Issue: 07, May-2014

[7] S.K. Jain, S.P. Kurhekar and Chetan Wadekar, "Strength analysis of bamboo and steel reinforced concrete Beam" Engineering\& Technology in India; Volume 6, Issue 1, April-2015

[8] Bindu m, Narendra b.k, Manjunathaj.k, "Bamboo Fiber Reinforced Concrete a Review" International Journal of Science Technology and Management Vol. No. 5, Issue No. 06, June2016

[9] Abdul Ahad, ZishanRaza Khan, Shumank Deep Srivastava, "Application of Steel Fiber in Increasing the Strength, Life-Period and Reducing Overall Cost of Road Construction (by Minimizing the Thickness of Pavement)" World Journal of Engineering and Technology, 2015, 3, 240-250 Published Online November-2015

[10] AjinkyaKaware, U.R.Awari, M.R.Wakchaure, "Material in Concrete Structure" International Journal of Innovative Research in Science, Engineering and Technology Vol. 2, Issue 6, June2013 


\section{AUTHORS' BIOGRAPHY}



Dr. Jayeshkumar Pitroda., received his Bachelor of Engineering Degree in Civil Engineering from Birla Vishwakarma MahavidyalayaEngineering College, Sardar Patel University in 2000. In 2009 he received his master's degree in Construction Engineering and Management form Birla Vishwakarma Mahavidyalaya Sardar Patel University. In 2015 he received his Doctor of Philosophy (Ph.D.) Degree in Civil

Engineering from Sardar Patel University. He joined Birla Vishwakarma Mahavidyalaya Engineering College as a faculty in 2009, where he is Assistant Professor of Civil Engineering Department with a total experience of 16 years in the field of Research, Designing and Education. He is guiding M.E. / M.Tech (Construction Engineering and Management) thesis work in the field of Civil / Construction Engineering. He has published many papers in National / International Conferences and International Journals. He has published seven Research Books in the field of Civil Engineering, Rural Road Construction, National Highways Construction, Utilization of Industrial Waste, Fly Ash Bricks, Construction Engineering and Management, Eco-friendly Construction.

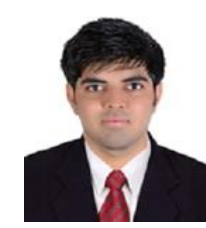

Hardik N. Pankhaniya, is student of final year, B.E. Civil Engineering., BVM Engineering College, Vallabh Vidyanagar-Gujarat-India.

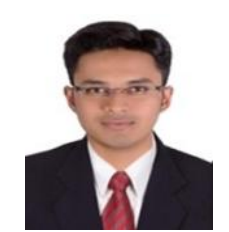

Urvish A.Pachani, is student of final year, B.E. Civil Engineering., BVM Engineering College, Vallabh Vidyanagar-Gujarat-India.

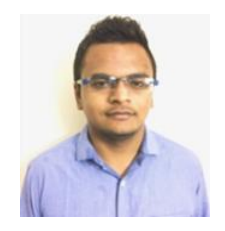

Saurabh C.Agravat, is student of final year, B.E. Civil Engineering., BVM Engineering College, Vallabh Vidyanagar-Gujarat-India.

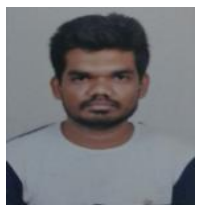

Prakash Parmar, is student of final year, B.E. Civil Engineering., BVM Engineering College, Vallabh Vidyanagar-Gujarat-India. 